http://jmscr.igmpublication.org/home/

ISSN (e)-2347-176x ISSN (p) 2455-0450

crossref DOI: https://dx.doi.org/10.18535/jmscr/v8i1.01

\title{
The Prevalence and the Outcome of Twin Pregnancies in a South-South Nigerian Tertiary Hospital
}

\author{
Authors \\ Abah Matthias Gabriel*, Bassey Emem Abasi, Ovie David Okupa \\ University of Uyo Teaching Hospital, Uyo. Nigeria. \\ *Corresponding Author \\ Dr Abah, Matthias Gabriel \\ Department of Obstetrics and Gynaecology \\ University of Uyo, P.M.B.1017, Uyo, Akwa Ibom state Nigeria
}

\begin{abstract}
Twinning is the commonest form of multiple pregnancy, and it is associated with increased adverse perinatal and maternal outcomes. A 5-year retrospective observational study of all cases of twin gestations delivered at the University of Uyo Teaching Hospital was conducted to determine the prevalence as well as document the maternal and perinatal outcomes associated with it. There were 219 twin deliveries during the study period, accounting for $2.17 \%$ of all deliveries. Twinning accounted for $98.65 \%$ of all multiple births during the period under review. The majority (62.1\%) of the women were between 20 and 29 years of age, their mean age was 28.6 years, multiparous women (69.9\%), mean parity was 2.7, and booked status $(58.0 \%)$. The preterm delivery rate was $32.4 \%$, the caesarean section rate was $42.9 \%$ and the perinatal mortality rate (PNMR) was 87 per 1000 births. Maternal complications included a high operative delivery rate of $42.8 \%$, hypertensive disorders (9.6\%), anaemia (2.7\%) and $4.1 \%$ of postpartum haemorrhage. The perinatal morbidity and mortality and maternal morbidity rates were high. A significant percentage of the women with these high risk pregnancies were unbooked thereby reducing the opportunity for early detection and management in our environment. There is need for community education and advocacy on early booking and regular antenatal visits and better resources in our maternity unit to improve foetomaternal outcomes of twin.

Keywords: Morbidity, Pregnancy, Multiple, Prevalence, Twins.
\end{abstract}

\section{Introduction}

Pregnancy and birth involving more than one foetus and baby are peculiar and have thrilled mankind for centuries. Twinning is the commonest form of multiple gestation; accounting for $97 \%$ of multiple pregnancies and $1 \%$ of all pregnancies and. ${ }^{1,2}$ It is often associated with increased adverse perinatal and maternal outcomes. and also poses significant management challenges for the medical health professional. ${ }^{2,3}$ The aetiology of multiple pregnancies is thought to be related to zygosity. While monozygotic twinning is a random occurrence of unknown aetiology, dizygotic twinning is believed to be a product of multiple follicle ovulation caused by increased gonadotropin levels. ${ }^{4}$ 
The frequency of twinning in pregnancy varies widely between developed and developing nations and is directly related to zygosity. ${ }^{5,} 6$ The incidence of twins ranges from the least common 4 per 1000 births in Japan to the most common 54 per 1000 in Southwest Nigeria. ${ }^{7}$ The incidence of monozygotic twins is constant worldwide at approximately four per 1000 births while that of multiple zygotic pregnancies varies in relation to maternal age, the use of assisted reproductive technology (ART), and ethnicity in several ways. ${ }^{8}$ An increase in maternal age and fertility treatment are believed to be responsible for the current increase in twinning rates in developed countries. ${ }^{5}$ It has been found that one-fourth to one-third of the increase in twin or triplet pregnancies are attributable to a contemporaneous increase in maternal age, while $30 \%$ to $50 \%$ of twin pregnancies and at least $75 \%$ of triplet pregnancies occur after infertility treatment in countries with high occurrence of multiple births. ${ }^{8}$ Twin pregnancy is associated with significant increase in maternal mortality and morbidity. Maternal complications documented to be associated with twin pregnancies include hyperemesis gravidarum, anaemia, hypertension, polyhydramnios as well as antepartum haemorrhage. $^{3,9}$ There is also an increased incidence of gestational diabetes, urinary tract infection, premature rupture of foetal membranes, operative delivery and postpartum haemorrhage. ${ }^{9}$ ${ }^{10}$.Peripartum problems associated with twin pregnancy and delivery include an increase in perinatal mortality often resulting from prematurity, a consequence of preterm birth, and intrauterine growth restriction. ${ }^{3,11}$

The well documented higher incidence of spontaneous twin pregnancy and birth among Africans especially in Southwest, Nigeria $^{7}$ warrants a study of twinning rates in other regions of the country. The greater perinatal morbidity and mortality associated with twins as well as the barrage of maternal complications that could accompany it, and the resultant management challenges it poses for obstetricians calls for a periodic review of twin births in all maternity centres. It is in the light of the foregoing that this 5 -year review was carried out in the obstetric unit of the University of Uyo Teaching Hospital in South-south Nigeria. The specific objectives of the study were to determine the prevalence of twin pregnancies, and document the maternal and perinatal morbidities and mortality associated with twin births in the centre. This we hope will not only help us improve our management of the condition but would add to the body of knowledge on this very important subject.

\section{Materials and Methods}

This was a retrospective observational study of all cases of twin pregnancies delivered at the University of Uyo Teaching Hospital spanning a five-year period which started from 1st January 2011 through 31st December 2015. The sources of data were the labour ward admissions register, the obstetrics theatre records, and the Special and sick babies `unit admissions records. The records of all deliveries that took place during the period were reviewed and the hospital numbers of all patients documented either as multiple or twin births were collected. The case records of those with twin deliveries were retrieved from the medical records department for in-depth study. Complementary information was obtained from the babies' case notes in the neonatal unit. These case notes were analyzed. Information abstracted included maternal age and parity, booking status, gestational age at birth, mode of delivery, gender distribution, birth weight, and perinatal and maternal outcome. The data obtained were entered into a proforma designed for the study and results presented in frequency tables and percentages.

\section{Results}

During the study period, there were ten thousand and one hundred and two $(10,102)$ deliveries at an average of about 2000 deliveries per year; with the years, 2012 and 2014 having the highest (21.43\%) and lowest $(18.62 \%)$ respectively. There were 222 multiple births, accounting for $2.2 \%$ of 
deliveries. There were 219 twin deliveries, accounting for $2.17 \%$ of total deliveries and $98.65 \%$ of multiple births (Table 1).

The socio-demographic characteristics of women who had twin deliveries during the 5-year period showed that the majority of the women were between 20 and 29 years(62.1\%), followed by those from 30 to 39 years(37.1\%). The mean age was 28.6years. One hundred and fifty-three (69.9\%) had between 2 and 4 previous deliveries, while $25.1 \%$ were primiparous women. The mean parity was 2.7 . Most (58.0\%) of the women were booked. (Table 2)

The majority of women with twin pregnancies were delivered at term $(67.6 \%)$ while the preterm delivery rate was $32.4 \%$. There were no post term births. (Table 3).

One hundred and seventeen (53.4\%) women had spontaneous vaginal delivery while the Caesarean section rate associated with twin delivery was
42.9\%. The Assisted vaginal breech delivery and instrumental deliveries rates were $2.3 \%$ and $1.4 \%$ respectively. (Table 4)

There were 208 male twin births and 230 female twin births giving a male : female ratio of 1:1.1. There were more male first twin and female second twin,(Table 5) A significant proportion of the babies were of low birth weight $(36.1 \%)$, while $32.4 \%$ and $3.0 \%$ were premature and had birth asphyxia respectively. There were 38 stillbirths and no early neonatal deaths. The perinatal mortality rate (PNMR) was 87 per 1000 total births. (Table 6)

Maternal morbidities associated with twin pregnancies and deliveries in this study included a high caesarean delivery rate of $42.8 \%$, preterm labour, $26.5 \%$ while medical complications were mainly hypertensive disorders and anaemia at $9.6 \%$ and $2.7 \%$ respectively. Nine women $(4.1 \%)$ had postpartum haemorrhage.(Table 7)

Table 1: Yearly distribution of Deliveries in the University of Uyo Teaching Hospital from $1^{\text {st }}$ January 2011 to $31^{\text {st }}$ December, 2015

\begin{tabular}{|c|c|c|c|c|c|c|}
\hline \multirow[t]{2}{*}{$\mathbf{S} / \mathbf{N}$} & \multirow[t]{2}{*}{ Year } & \multirow[t]{2}{*}{ Singleton } & \multicolumn{2}{|c|}{ Multiple } & \multirow[t]{2}{*}{ Total } & \multirow[t]{2}{*}{ Percentage $(\%)$} \\
\hline & & & Twins & Triplets & & \\
\hline 1. & 2011 & 1942 & 31 & 1 & 1974 & 19.54 \\
\hline 2. & 2012 & 2121 & 43 & 1 & 2165 & 21.43 \\
\hline 3. & 2013 & 1987 & 56 & 0 & 2043 & 20.22 \\
\hline 4. & 2014 & 1831 & 50 & 0 & 1881 & 18.62 \\
\hline 5. & 2015 & 1999 & 39 & 1 & 2039 & 20.18 \\
\hline \multicolumn{2}{|c|}{ Total } & 9880 & 219 & 3 & 10,102 & 100 \\
\hline \multicolumn{3}{|c|}{ Percentages (\%) 97.8} & 2.17 & 0.03 & 100 & \\
\hline
\end{tabular}

Total number of Multiple birth $=222$

Twins $=98.65 \%$ of multiples; Twin birth rate $=21.7 / 1000$ deliveries

Table 2: Characteristics of women who delivered twin in UUTH, 2011-2015

$\begin{array}{lcc}\text { Variable } & \text { Number } & \text { Percentage (\%) } \\ \text { Age distribution (Years) } & & \\ <20 & 3 & 1.4 \\ 20-29 & 136 & 62.1 \\ 30-39 & 79 & 36.1 \\ =/>40 & 1 & 0.5 \\ \text { Parity } & & \\ 1 & 55 & 25.1 \\ 2-4 & 153 & 69.9 \\ >/=5 & 11 & 5.02\end{array}$




\section{JMSCR Vol||08||Issue||01||Page 01-08||January}

Booking status

Booked

167

76.3

Unbooked

Total

219

100

Table 3: Gestational Age at birth (weeks)

$\begin{array}{lcc}\text { Gestational age } & \text { Frequency } & \text { Percentage } \\ <37 \text { (Preterm) } & 71 & 32.4 \\ 37-42(\text { Term }) & 148 & 67.6 \\ >42(\text { Post-term) } & 0 & 0 \\ \text { Total } & \mathbf{2 1 9} & \mathbf{1 0 0}\end{array}$

Table 4: Methods utilised in delivery of twins in UUTH, 2011-2015

Method

Normal Vaginal Delivery (SVD)

Frequency Percentage $(\%)$

Caesarean section

117

53.4

94

42.9

Instrumental (Vacuum)

Assisted breech delivery

Total

$3 \quad 1.4$

$5 \quad 2.3$

$219 \quad 100$

Table 5: Sex Distribution of Twins in UUTH, 2011-2015

Variables

Frequency

Percentage $(\%)$

Twin 1 : Twin 2 Total

Males

111

97 208

Females 108

122

230

52.5

Approximate Male: Female Ratio 1:1.1 with Female preponderance

Table 6: Perinatal Risks and complications ${ }^{\dagger}(n=438)$

Variable

Stillbirth

Low birth-weight

Prematurity

Birth Asphyxia
Frequency Percentage $(\%)$

$\begin{array}{cc}38 & 8.7 \text { PNMR = Approximately 87/1000 total births } \\ 158 & 36.1 \\ 142 & 32.4 \\ 13 & 3.0\end{array}$

†Some babies had multiple complications

Table 7: Maternal Morbidities ${ }^{\S}(\mathrm{n}=219)$

Variable

Anaemia

Hypertension/PE

Preterm labour

Postpartum Haemorrhage

Caesarean section Frequency

6

21

58

9

94

${ }^{\S}$ Few mothers had multiple morbidities

\section{Percentage (\%)}

2.7

9.6

26.5

4.1

42.9 


\section{Discussion}

The prevalence of multiple births during the study period was $2.2 \%$ with twin pregnancies accounting for $98.6 \%$ of these deliveries, the twinning rate in this study was $21.7 / 1000$ births. The prevalence rate of twin gestation in this study is higher than the $1.6 \%$ reported in Port-Harcourt, Nigeria, ${ }^{12}$ but lower than documented prevalence rates of 2.2\%, 2.6\% and 2.8\% in Enugu and Bida, both in Nigeria and an Ethiopian provincial hospital respectively. ${ }^{13-15}$ The prevalence from this study is much higher than ones reported from developed parts of the world like Asia and Australia, Europe and the United States of America with spontaneous twin rates of $0.6 \%$ and $1-2 \%$ respectively. ${ }^{16}$ The relatively wide variation in magnitude of twin delivery could be due to the ethnic differences in Africa. While it is widely recognized that the prevalence of twining is rising globally due to the increased use of assisted reproductive technology (ART), the rate remains highest in Africa as it is influenced by racial and probably dietary factors with highest rates reported from south-west Nigeria. ${ }^{17,18}$

Most (58.0\%) of the women were booked, a value less whan was demonstrated in an earlier review in the same centre where $79.3 \%$ of mothers with twin pregnancy registered for antenatal care. ${ }^{19}$ This is in contrast to findings from a rural mission tertiary hospital in the Niger delta, Nigeria where $65.7 \%$ of women with twin pregnancies were unbooked. ${ }^{20}$ Our study was carried out in a tertiary facility located in an urban area and this may be responsible for the high booking rates documented. This Rural-urban differences in the utilization of antenatal care services, with a higher proportion of urban women utilizing these services than rural women had also been found both in the National health surveys and a Southeast, Nigerian study. ${ }^{21,22}$ While the booking rate is above the National average for antenatal care of $51 \%,{ }^{21}$ it can still be said to be low for a high risk pregnancy that twin pregnancies have been adjudged to be and the needed closer monitoring for early detection of complications.
The relationship between increasing maternal age, parity and increased incidence of multiple pregnancies is documented and this is usually thought to be secondary to physiological hormonal changes such as increased follicle stimulating hormone(FSH) secretion. ${ }^{16,17,23}$ In our study however, the modal age range of 20 to 29 years and mean age was 28.6 years is at variance with accepted knowledge but is similar to findings from some studies, ${ }^{14}, 24$ This differences in findings may a product of differences in study designs as ours was hospital-based and may not reflect the true picture of the general population. The majority of the mothers in this study were multipara with a mean parity of 2.7 , a pattern of relationship found in most studies. ${ }^{14,20,25}$

The caesarean section rate associated with twin delivery in this study was high at $42.9 \%$, a rate close to $48.0 \%$ and $53.5 \%$ reported from Enugu and Bida, Nigeria respectively. ${ }^{13,14}$ The caesarean section rate of twin pregnancies is reported to be twice that of singletons, rate believed to be a reflection of the high risk nature of these pregnancies with their attendant increased maternal and perinatal morbidity and mortality, and it is observed irrespective of the population based sample studied. ${ }^{26}$ The high caesarean section rate indicated for twin delivery here may be a reflection of the increased number of referred patients who would only achieve delivery through the abdominal route as $42.0 \%$ of the patients in this were unbooked and presented as referred emergencies. Also, vaginal birth of twins at term is well recognised as a high-risk area associated with increased rates of perinatal death and a depressed Apgar score, primarily because of intrapartum asphyxia of the second twin. ${ }^{27}$ There was a low instrumental vaginal delivery rate of $1.4 \%$ compared to $4 \%$ of twin deliveries reported in Delta state, Nigeria. ${ }^{20}$

The twin pregnancy preterm delivery rate of $32.4 \%$ found in our study is similar to $35.4 \%$ found in an earlier study in our centre, ${ }^{19}$ is comparable to $30.8 \%$ in Port Harcourt, ${ }^{12}$ but less than the preterm birth rates of $41.0 \%$ reported 
from Enugu. ${ }^{13}$ The commonest complication of twin gestation is preterm delivery which is also the main contributor to the high perinatal morbidity and mortality found in multiple pregnancies with $50 \%$ of twin pregnancies delivering before 37 weeks and 10\% delivering before 32 weeks of gestation. ${ }^{28,29}$

Hypertensive disorders of pregnancy were found in $9.6 \%$ of the women, while this is higher than that seen in singleton pregnancies; this is lower than that shown in a previous study in our centre and Umuahia, Nigeria. ${ }^{19,30}$ Twin pregnancies has been documented to be associated with a 2 to 3 fold increased risk of hypertensive diseases when compared to singleton gestation. This is thought to be related to hyperplacentosis as well as the association of rising maternal age with multiple gestation and chronic illnesses predisposing to hypertension in pregnancy. ${ }^{26,31}$ Other maternal complications found in this study included postpartum haemorrhage $(4.1 \%)$ and anaemia $(2.7 \%)$. The exaggerated physiological changes, over distension of uterus and interventions in pregnancy and delivery of twin pregnancies predispose to anaemia and post-partum haemorrhage; and these had been corroborated by other studies with similar findings. ${ }^{13}, 19,26,31$

The perinatal mortality rate in this study was 87/ 1000 births, which is close to $80 / 1000$ and 88.5/1000 births seen in Jos and Bida, Nigeria respectively, but it is however lower than the $100 / 1000$ and $207 / 1000$ found in previous studies in Nigeria. ${ }^{14,19,32,33}$ The still birth rate was $8.7 \%$ while the rate of birth asphyxia was strikingly very low at $3.0 \%$. It was also noted, albeit interestingly that no early neonatal death was recorded among the twin-births. This may be a reflection of the very low rate of neonatal asphyxia found in this study. The Perinatal mortality is said to be five times higher in twins compared to singletons unrelated to mode of delivery. ${ }^{27}$ The rates of other perinatal complications such as low birth weight and prematurity were $36.1 \%$ and $32.4 \%$ respectively. The association of low birth weight with twin pregnancy is well documented, occurring in almost half of twin gestations and may be associated with preterm delivery, foetal growth restriction, foetal malformations, placentation and infection. ${ }^{23}$

In conclusion, the perinatal morbidity and mortality as well as maternal morbidity rates associated with twin pregnancies were high. A significant percentage of the women with these high risk pregnancies were unbooked thereby reducing the opportunity for early detection and management in our environment. This has important economic and social implications and increases the burden on our stretched healthcare delivery system. We therefore recommend increased community education and advocacy on the increased risk associated with twin gestation, the need for early booking and regular and more frequent antenatal visits which we believe could assist timely identification of complications and allow necessary interventions to prevent same and improve foetomaternal outcomes. There is also the need for an improvement of the resources in our maternity unit to cope with these challenges.

\section{Acknowledgements}

The contribution of the staff of the Department of Health records and statistics, Obstetric and Special care baby units of the University of Uyo Teaching Hospital; Uyo to the success of this review is highly appreciated.

\section{References}

1. Dube J, Dodds L, Armson A. Does chorionicity or zygosity predict adverse perinatal outcomes in twins? Am J Obstet Gynaecol.2002; 186: 579-83.

2. Dera A, Breborowicz GH, Keith L. Twin pregnancy-physiology, complications and the mode of delivery. Arch perinat Med 2007; 13(3): 7-16

3. Norwitz ER, Edusa V, Park JS. Maternal physiology and complications of multiple pregnancy. Semin Perinatol. 2005;29:33848 
4. Heard AJ, Ramus RM. Multifoetal pregnancy. Medscape. Available at: www.emedicine.medscape.com/article/161 8038overview No.3 [accessed 22/4/2015].

5. Pison J, D'Addato AV. Frequency of twin birth in developed countries. Twin Res Hum Genet 2006April;9(2): 250-9.

6. Smits J, Monden C. Twinning across the developing world. PLoS One. 2011;6(9):ee25239; Epub 2011 Sep 28 Available at www.ncbi.nih.gov/pubmed/21980404 [accessed 19/4/2015]

7. Kilby MD, Oepkes D. Multiple pregnancy In: Edmonds DK.(Editor), Dewhurst's Textbook of Obstetrics and Gynaecology, 8th Edition. UK, Wiley-Blackwell 2012; 230-261.

8. Blonde B, Kaminski M. Trends in the occurrence, determinants, and consequences of multiple births. Seminars in perinatology. 2002; 28(4): 239-249.

9. Chowdhury S, Hussain MA. Maternal complications in twin pregnancies. Mymensingh Med J. 2011; Jan 20(1): 837.

10. Multiple Pregnancy: Maternal risks and complications. Available at www.healthcommunities.com/pregnancy/ multiple-pregnancy-risks-maternal.shtml [Accessed 13/05/2018]

11. 'Loos RJ, Derom C, Derom R, Vlietinck R. Determinants of birthweights and intrauterine growth in liveborn twins. Paediatric Perinat Epidimio 2005; 19: 1522.

12. Bassey G, Inimgba NM. Feto -maternal outcome of term gestation in Port-Harcourt South- South Nigeria. Niger J Med. 2014; 23(4):282-287.

13. Nwankwo TO, Aniebue UU, Ezenkwele E, Nwafor MI. Pregnancy outcome and factors affecting vaginal delivery of twins at the University of Nigeria teaching hospital, Enugu. Niger J Clin pract.2013; 16(4):490-495.

14. Adewale FB, Ashimi A, Oyepopo OA. Trends of multiple births at Federal medical centre Bida, North-central Nigeria. Trop J Obstet Gynaecol. 2018; 35:68-72.

15. Ayza A, Tilahun T, Bedada D. Magnitude and Obstetric Complications of Twin Deliveries at Nekemte Referral Hospital, Western Ethiopia: Facility-based Case Control Study. Biol Med (Aligarh) 2018; 10: 453. doi:10.4172/0974-8369.1000454

16. Ananth CV, Chauhan SP (2012) Epidemiology of Twinning in Developed Countries. Seminars in Perinatology, 36:156-161.

17. Dera A, Breborowiczg H, Keith L.Twin pregnancy - physiology, complications and the mode of delivery. Archives of Perinatal Medicine. 2007; 13:1673-1675

18. Bakare A, Akinboro A, Azeez M. Frequency of twinning in southwest Nigeria. Indian Journal of Human Genetics. 2008; 14:41-47

19. Abasiattai AM, Umoiyoho AJ, Utuk NM, Shittu DG. Incidence and mode of delivery of twin pregnancies in Uyo, Nigeria. Niger Med J. 2010;51:170-2.

20. Igberase GO, Ebeigbe PN, Bock-Oruma A. Twinning rate in a rural mission tertiary hospital in the Niger delta, Nigeria. J Obstet Gynaecol. 2008;28 (6): 586-589. doi: 10.1080/01443610802344308

21. National Population Commission (NPC)[Nigeria]. Nigeria Demographic and Health Survey 2013. Calverton, Maryland, USA: national population Commission and ICF Macro.

22. Duru CB, Eke NO, Ifeadike CO, Diwe $\mathrm{KC}$, Uwakwe KA, Nwosu BO et. al. Antenatal Care Services Utilization among Women of Reproductive Age in Urban and Rural Communities of South East Nigeria: 
A Comparative Study. Afrimedic Journal 2014;5(1):50-58

23. Blonde B, Kaminski M. Trends in the occurrence, determinants, and consequences of multiple births. Seminars in perinatology. 2002; 28(4): 239-249.

24. Tilahun T, Araya F, Tura G. Incidence and risk factors of twin pregnancy at Jimma specialized hospital, Southwest Ethiopia. Epidemiology (Sunnyvale). 2015; 5:188. Doi: 10.4172/2161 1165.1000186

25. Aisien AO, Olarewaju RJ, Imide GE. Twins in Jos, Nigeria: A seven -year retrospective study. Med Sci Monit.2000;6 (5): 945-50.

26. Danielly SS, Fernanda GS, Jose GC. Multiple Pregnancy: Epidemiology and association with maternal and perinatal morbidity. Rev. Bra. Ginecol. Obstet. 2018;40(9): 554-562.

27. Breeze A, Smith G. Risk management: Mode of delivery of twins. The Obstetrician \& Gynaecologist.2004;6:222226. Available at: https://obgyn.onlinelibrary.wiley.com/doi/ pdf/10.1576/toag.6.4.222.27019

28. Murray SR, Stock SJ, Cowan S, Cooper ES, Norman JE. Spontaneous preterm birth prevention in multiple pregnancy. The Obstetrician \& Gynaecologist 2018;20;5763. DOI: $10.1111 / \operatorname{tog} .12460$.

29. Pyrbot JE, Agarwal M. Twin pregnancymaternal and fetal complications its association with mode of delivery: A study in a tertiary center. Int $\mathrm{J}$ Reprod Contracept Obstet Gynecol 2017;6:508994.

30. Oraekwe IO. Appraisal of maternal outcome of twin gestation. Saudi J Health Sci.2018; 7:163-6.
31. Akaba GO, Onafowokan O, Agida TE, Offiong RA, Achonwa CJ. Fetal outcome of twin gestations in a Nigerian teaching hospital. Niger J Med.2013;22(1): 48-51.

32. Daru PH, Ajang M, Pam IC, Okpe S, Kigbu JH. Twin mortality in a tertiary hospital in Central Nigeria. J. Med Trop. 2010; 12(2):

33. Attah RA, Mohammed Z, Gogir M, A review of twin deliveries in Aminu Kano Teaching Hospital, North-west Nigeria. Niger J Basic Clin Sci 2014;11:3-7. 